\title{
Correction to: Innovations in Electronics and Communication Engineering
}

\author{
H. S. Saini, R. K. Singh, Mirza Tariq Beg, and J. S. Sahambi
}

\section{Correction to: \\ H. S. Saini et al. (eds.), Innovations in Electronics and Communication Engineering, Lecture Notes in Networks and Systems 107, https://doi.org/10.1007/978-981-15-3172-9}

In the original version of the book, the following belated corrections have been incorporated as in below:

Chapter "Performance Evaluation of Various Modulation Techniques for Underwater Wireless Optical Communication System": The author affiliation "Department of Electrical and Electronics Engineering, Khulne University of Engineering and Technology, Khulna, Bangladesh" has been changed to "Department of Electrical and Electronic Engineering, Khulna University of Engineering \& Technology, Khulna, Bangladesh".

Chapter "A Comparative Study on LSB Replacement Steganography". The author affiliation of Srinivas Bachu from "MLRIT, Hyderabad, India" to "Marri Laxman Reddy Institute of Technology and Management, Hyderabad, India".

The updated version of these chapters can be found at https://doi.org/10.1007/978-981-15-3172-9_11

https://doi.org/10.1007/978-981-15-3172-9_57 